\title{
Are we scientifically ready to adopt tranexamic acid as a routine in arthroplasty?
}

\author{
Traneksamik asidi bir artroplasti rutini olarak benimsemeye bilimsel olarak hazır mıyız?
}

\author{
Erdem Aras Sezgin, $M^{1}{ }^{1}$, O. Şahap Atik, $M^{2}{ }^{2}$ \\ 'Department of Orthopedics and Traumatology, Gazi University Medical Faculty, Ankara, Turkey \\ ${ }^{2}$ Professor of Orthopedic Surgery, Turkish Joint Diseases Foundation, Ankara, Turkey
}

The orthopedic literature is abundant in studies on use of tranexamic acid (TXA); most showing its effectiveness in reducing blood loss and transfusion requirement leading to better outcome, shorter length of hospital stay and reduced costs. ${ }^{[1,2]}$ History of TXA dates back to 1960s and TXA is a relatively cheap agent. However, being old and cheap have not restrained TXA to revolutionize the perioperative blood management in the last decade of orthopedic practice, particularly in arthroplasty procedures which make up for a big portion of elective surgeries. ${ }^{[3-5]}$ However, despite the great interest in and the enthusiasm surrounding this agent, its pharmacokinetic characteristics, dosing and optimal modality of administration for different clinical scenarios still remain largely unknown. Tranexamic acid is a fibrin clot stabilizer and not actually a pro-coagulant agent, but it is still commonly associated with increased risk of venous thromboembolic events (VTEs) (e.g. stroke, deep venous thromboembolism, pulmonary embolism), myocardial infarction and to a lesser extent, retinal injury, seizures and nausea. Although this increased risk profile has not been demonstrated, neither it has been totally ruled out in arthroplasty procedures. Considering that even the meta-analyses including data from highest quality randomized controlled trials struggle to provide concrete evidence on safety of TXA use and, for prospective studies, there is need for at least 5,000 patients in each group even to detect a $1 \%$ difference with an $80 \%$ power, TXA's widespread adoption seems to continue lacking strong scientific background. ${ }^{[6,7]}$ It has also not been approved by the U.S. Food and Drug Administration for uses other than dental bleeding prophylaxis in hemophilic patients and menorrhagia. ${ }^{[8,9]}$

Despite the aforementioned negativity about TXA's use, available studies with highest quality demonstrate successful results without detecting increased risk, which makes the agent a good option for managing blood loss in selected patients, ${ }^{[10,11]}$ to the extent that it has recently been suggested that relinquishing tourniquet use can improve total knee arthroplasty outcome by utilizing TXA. ${ }^{[12,13]}$ However, there is great heterogeneity in the literature, where different intravenous (IV), topical, oral or combinations of TXA regimens do not clearly outweigh the others. ${ }^{[7,14]}$ Although topical administration is theoretically thought to have less risk for systemic complications, this effect has also not been clinically demonstrated. Single or multiple dose IV administrations of 10 to $30 \mathrm{mg} / \mathrm{kg}$ TXA before and/or after the procedure, topical administration of 1 to $3 \mathrm{~g}$ TXA in $50 \mathrm{~mL}$ of saline at the end of the procedure, multi-dose $650 \mathrm{mg}$ tablets of oral TXA, and combination of these are the commonly reported administration modalities. ${ }^{[11,12,15,16]}$ Furthermore, the literature has not shown an increased risk of VTE in low-risk patients while there are no reliable data on high-risk patients with positive VTE history.

It should be considered that VTE prophylaxis for arthroplasty patients by itself hosts many controversies; 
therefore, it seems unlikely that data on TXA use in high-risk patients will be available in the near future. ${ }^{[17]}$ In addition, it should not be forgotten that available data on safety inevitably rely on statistically underpowered trials. Until the literature provides concrete data, use of TXA in arthroplasty procedures should be limited to selected patients and efforts should be focused on utilizing the lowest TXA dose possible and determining the optimal administration route while patients should be instructed in detail about current scientific uncertainty.

\section{Declaration of conflicting interests}

The authors declared no conflicts of interest with respect to the authorship and/or publication of this article.

\section{Funding}

The authors received no financial support for the research and/or authorship of this article.

\section{REFERENCES}

1. Aydın BK, Durgut F, Erkoçak ÖF, Acar MA. Other benefits of intra-articular injection of tranexamic acid in primary total knee arthroplasty apart from reducing blood transfusion rates. Eklem Hastalik Cerrahisi 2017;28:25-9.

2. Atik OS. Does tranexamic acid reduce blood loss and blood transfusion requirement in knee arthroplasty? Eklem Hastalik Cerrahisi 2012;23:166-7.

3. Watts G. Utako Okamoto. Lancet 2016;387:2286.

4. Brusalis CM, Bostrom MPG, Richardson SS. Has Tranexamic Acid in Total Knee Arthroplasty Made Tourniquet Use Obsolete? HSS J 2018;14:338-40.

5. Pap K, Vasarhelyi G, Gal T, Nemeth G, Abonyi B, Hangody LR, et al. Evaluation of clinical outcomes of cemented vs uncemented knee prostheses covered with titanium plasma spray and hydroxyapatite: A minimum two years follow-up. Eklem Hastalik Cerrahisi 2018;29:65-70.

6. Muñoz M, Páramo JA. Antifibrinolytic agents in current anaesthetic practice: use of tranexamic acid in lower limb arthroplasty. Br J Anaesth 2014;112:766-7.

7. Wang Z, Shen X. The efficacy of combined intra-articular and intravenous tranexamic acid for blood loss in primary total knee arthroplasty: A meta-analysis. Medicine
(Baltimore) 2017;96:e8123.

8. U.S. Food \& Drug Administration. Cyklokapron (tranexamic acid) labeling-package insert. Drugs@FDA: FDA Approved Drug Products; 2013. Available at: https://www.accessdata. fda.gov/drugsatfda_docs/label/2011/019281s030lbl.pdf

9. U.S. Food \& Drug Administration. Lysteda (tranexamic acid) labeling-package insert. Drugs@FDA: FDA Approved Drug Products; 2013. Available at: https://www.accessdata. fda.gov/drugsatfda_docs/label/2013/022430s004lbl.pdf

10. Fillingham YA, Ramkumar DB, Jevsevar DS, Yates AJ, Shores P, Mullen K, et al. The Efficacy of Tranexamic Acid in Total Knee Arthroplasty: A Network Meta-Analysis. J Arthroplasty 2018;33:3090-8.e1.

11. Fillingham YA, Ramkumar DB, Jevsevar DS, Yates AJ, Shores P, Mullen K, et al. The Efficacy of Tranexamic Acid in Total Hip Arthroplasty: A Network Meta-analysis. J Arthroplasty 2018;33:3083-9.e4.

12. Huang Z, Xie X, Li L, Huang Q, Ma J, Shen B, et al. Intravenous and Topical Tranexamic Acid Alone Are Superior to Tourniquet Use for Primary Total Knee Arthroplasty: A Prospective, Randomized Controlled Trial. J Bone Joint Surg [Am] 2017;99:2053-61.

13. Tuncalı B, Boya H, Kayhan Z, Araç Ş. Obese patients require higher, but not high pneumatic tourniquet inflation pressures using a novel technique during total knee arthroplasty. Eklem Hastalik Cerrahisi 2018;29:40-5.

14. Fillingham YA, Ramkumar DB, Jevsevar DS, Yates AJ, Bini SA, Clarke HD, et al. Tranexamic Acid Use in Total Joint Arthroplasty: The Clinical Practice Guidelines Endorsed by the American Association of Hip and Knee Surgeons, American Society of Regional Anesthesia and Pain Medicine, American Academy of Orthopaedic Surgeons, Hip Society, and Knee Society. J Arthroplasty 2018;33:3065-9.

15. Lacko M, Cellar R, Schreierova D, Vasko G. Comparison of intravenous and intra-articular tranexamic acid in reducing blood loss in primary total knee replacement. Eklem Hastalik Cerrahisi 2017;28:64-71.

16. Fillingham YA, Darrith B, Calkins TE, Abdel MP, Malkani AL, Schwarzkopf R, et al. 2019 Mark Coventry Award: A multicentre randomized clinical trial of tranexamic acid in revision total knee arthroplasty: does the dosing regimen matter?. Bone Joint J 2019;101-B:10-6.

17. Azboy N, Çimen O, Demirtaş A, Elçi S, Azboy İ. The changes in preferences for venous thromboembolism prophylaxis after total joint arthroplasty in Turkey: A survey. Eklem Hastalik Cerrahisi 2018;29:139-46. 